\title{
MANEJO E ADAPTAÇÃO DO GIRASSOL EM SOLOS DO CERRADO
}

Milena de Lima Vieira, Andréia Santos Cezário, Nariane Coelho de Oliveira, Larissa Cristhyna de Paula,Tiago Neves Pereira Valente, Wallacy Barbacena Rosa dos Santos, Jeferson Correa Ribeiro, Eliandra Maria Bianchini

Instituto Federal Goiano, Goiás. Email: andreia.cezario@ifgoiano.edu.br

\section{RESUMO}

O girassol (Heliantus anuus L.) pertence à família Asteraceae, fazendo parte de um gênero com aproximadamente 49 espécies catalogadas, onde 12 são espécies anuais e 37 são espécies perenes (UNGARO, 1990). Dentre as espécies, o Heliantus anuus L. se destaca por ser um cultivar que tem como característica vantajosa, a sua grande capacidade de adaptação, consequentemente uma maior resistência a seca, a temperaturas altas e temperaturas baixas, quando comparado a outras espécies cultivadas no Brasil. Com isso, o girassol se caracteriza como uma oleaginosa de grande importância agronômica. O girassol é muito utilizado para a produção de sementes e óleo, alguns pesquisadores também descrevem esse cultivar como uma planta de uso ornamental. É uma planta de qualidade, ciclo curto, boa produtividade e apresenta altos índices de rendimento de óleo. O girassol é uma boa alternativa de cultivo para o Cerrado brasileiro, uma vez que, suas características de adaptação e boa produção, viabilizam o seu cultivo em regiões produtoras de grãos. Desta forma, objetivou-se apresentar uma revisão de estudos e pesquisas que possam fornecer informações quanto ao desempenho do girassol em cultivo no cerrado, para possibilitar o sucesso na produção do mesmo, abordando o manejo cultural, controle de doenças, preparo de solo, entre outros fatores que influenciam a produção.

Palavras - chave: Cultivo, forrageira, Heliantus anuus $L$

\section{MANAGEMENT AND ADAPTATION OF SUNFLOWER IN CERRADO'S SOILS}

\begin{abstract}
The sunflower (Heliantus anuus L.) belongs to the family Asteraceae, being part of a genus with approximately 49 cataloged species, where 12 are annual species and 37 are perennial species (UNGARO, 1990). Among the species, Heliantus anuus L. stands out for being a cultivar that has as advantageous characteristic, its great capacity of adaptation, consequently a greater resistance to drought, to high temperatures and low temperatures, when compared to other species cultivated in Brazil. Therewith, the sunflower is characterized as an oleaginous of great agronomic importance. Sunflower is widely used for seeds and oil production and, some researchers also describe this cultivar as a plant for ornamental use. It is a plant with quality, with short cycles, good productivity and with has high oil yield indexes. The sunflower is a good cultivation alternative for the Brazilian Cerrado, since its characteristics of adaptation and good production, make possible its cultivation in grain producing regions. In this way, the objective of this work is to present a review of studies and researches that can provide information on the performance of the sunflower in cultivation in the cerrado, and to enable its success in the production of the same,approaching the cultural management, disease control, soil preparation and other factors that influence the production.
\end{abstract}

KEY WORDS: Cultivation, forage, Heliantus anuus $L$ 


\section{INTRODUÇÃO}

O cultivo do girassol (Helianthun annuus L.) tem se disseminado por vários países, em razão das suas utilidades, tais como a extração de óleo comestível de boa qualidade e por seu valor econômico. No Brasil, no ano de 1999 onde a produção do grão por área era de 33.200 ha, teve um aumento no ano de 2004 para 55.700 há. No Brasil, o cultivo do girassol é relativamente recente. A nível mundial, o girassol é a oleaginosa que se destaca como a quinta no quesito matéria prima, quarta em produção de farelo e terceira em produção mundial de óleo comestível, antecedendo a soja e a colza. Também se destaca entre as culturas anuais, sendo responsável por 16\% da produção mundial de óleo (VERSLYPE et. al., 2016; DE PAULA JÚNIOR, 2007).

Nos "levantamentos de safra" realizados pela Conab, no mês de dezembro/2015, a estimativa para a área de cultivo de girassol foi de 111.500 mil ha, já no mês de março/2016, a estimativa da safra 2015/16, teve uma queda na área de cultivo de 66,8\%, ou seja, 37.000 mil ha, segundo os produtores, isto ocorreu devido às condições climáticas menos favoráveis no período de plantio do girassol, e também devido ao preço do girassol que não acompanhou os preços do milho nas regiões de produção (CONAB, 2016).

Pesquisas relatam que a cultura do girassol teve início na época da colonização da região Sul do Brasil. No período agrícola de 1964/65, o girassol atingiu uma produção de aproximadamente 4 milhões de toneladas de grãos, em uma área aproximada de 3.000 ha, ainda assim, não obtendo sucesso devido à falta de tecnologias de produção para as condições climáticas do Brasil. O girassol proporciona várias opções de uso, bem como a maioria das outras espécies, sendo utilizada tradicionalmente o consumo do fruto in natura na alimentação de aves. Quanto aos processos de melhoramento genético em desenvolvimento da cultura e destinação de frutos, foram redirecionados para o que hoje, é a principal finalidade da produção de girassol, que é a extração de óleo (GAZZOLA et. al., 2012).

O agronegócio tem papel importante no desenvolvimento econômico do Brasil, e dentro do agronegócio nacional, existem complexos industriais que se destacam tanto pela importância socioeconômica, quanto pela organização estrutural, tais como o da soja e o da carne. Dentre esses, estão presentes aqueles que têm uma relação com a exploração do girassol. Para um bom desempenho da lavoura de girassol, é necessária uma atenção à escolha da época de semeadura, ao genótipo, ao manejo adequado no que diz respeito a fertilidade do solo, levando em conta os sistemas de rotação e sucessão de culturas, além de fatores ambientais, tais como precipitação adequada e uniformidade durante o crescimento e desenvolvimento da cultura (PEREIRA et. al., 2016).

Segundo Brighenti e Castro (2013) a interação lavoura pecuária (iLP) relaciona-se com sistemas diversificados de produção de grãos, fibras, carnes e leite, implantados em uma mesma área, em sistemas como sucessão, consórcio e rotação. Entre as espécies produtoras de grãos, o girassol tem se tornado uma das opções técnicas, principalmente para os períodos de safrinha, sucedendo à cultura do milho ou da soja, tanto por suas características agronômicas, quanto por sua maior tolerância ao déficit hídrico e por sua baixa necessidade de insumos.

Em um experimento, Tomich et. al. (2003) avaliaram algumas características agronômicas de 12 híbridos de uma variedade de girassol (Helianthus annuus L.) que indicaram que, alguns híbridos de girassol possuem grande potencial para serem utilizados como um recurso forrageiro na produção de silagem no período de safrinha, ou nos períodos de seca ao ano. O girassol apresenta vantagens sobre as forrageiras tradicionais cultivadas, por ter um menor ciclo de produção, resistência ao frio e calor, e por sua alta capacidade de extração de água do solo, o que o classifica como uma boa opção para a produção de silagens em épocas de safrinha e até mesmo em locais que apresentam deficiência hídrica, que impossibilita o cultivo de outros cultivos, como por exemplo milho e sorgo. (PEREIRA et. al., 2016). 


\section{FATORES ECOFISIOLÓGICOS DO GIRASSOL}

O girassol é uma planta que tem boa adaptabilidade a variadas condições climática. Os grãos de pólen do girassol não são adaptados para serem transportados pelo vento, mas sim, transportados através de insetos, uma vez que esses grãos de pólen sejam caracterizados como pegajosos e pesados. É possível potencializar o crescimento e desenvolvimento do vegetal buscando o incremento na produção, quando associado a uma boa escolha da época de semeadura e um arranjo especial adequado, utilizando substâncias reguladoras de crescimento (DOS SANTOS et. al., 2016).

Com relação ao fotoperíodo, o girassol é uma planta classificada como insensível, e isso pode ser observado pela ampla dispersão, em regiões nacionais, dos híbridos e variedades de girassol, já testadas. Porém, alguns dos cultivares apresentam comportamentos diferentes, vez como planta de dia longo, vez como planta de dia curto (LEITE et. al., 2005).

Em um estudo, Lauriane et. al. (2015) avaliaram a fitomassa e a produção do girassol em função da irrigação com diferentes níveis de reposição hídrica, também utilizando adubação potássica sob condições de ambiente, e concluíram que, a interação entre os níveis de reposição hídrica com doses de potássio afetou significativamente a fitomassa seca do caule, da parte aérea e do capítulo. O déficit hídrico é o fator limitante de maior importância, no que diz respeito ao desenvolvimento das culturas. Porém, a planta do girassol é cultivada, com frequência, sem irrigação e, mesmo o girassol sendo considerado um cultivar que possui boa resistência à seca, sob condição de constante falta de água, a produção de grãos pode ser drasticamente afetada (BOYER, 1970; FARIAS, 2005).

Em um estudo Knapp et. al. (2016) avaliaram os efeitos da inoculação com Trichoderma sp. em conjunto com o déficit hídrico no crescimento e no desenvolvimento do girassol, e relataram que a inoculação das sementes do girassol utilizando Trichoderma sp. não apresentou diferenças significativas quanto ao desenvolvimento da cultura. Em solos com frequente falta de água, a temperatura se

torna o fator de maior limitação de germinação das sementes de girassol, uma vez que a germinação possui limitações de temperaturas, para continuidade de seu desenvolvimento (MACCHIA et. al.1985).

O déficit hídrico ocorrendo em alguns dos estádios mais importantes do desenvolvimento, irá afetar a produtividade da planta. É necessário que se aprimore o manejo de irrigação, visando uma melhor alocação dos recursos de água, uma vez que a agricultura dependa substancialmente disso. Com isso, a água economizada com o manejo de irrigação, pode ser utilizada para irrigar outras áreas e outras culturas (DA SILVA et. al. 2014; LOPES et. al., 2011).

\section{ADAPTABILIDADE E COMPORTAMENTO DO GIRASSOL}

A planta de girassol é uma oleaginosa que tem alto índice de crescimento no mundo, em termos de produção e área plantada. É de extrema importância que no momento de escolha da espécie, que leve-se em consideração, a espécie que tenha tolerância ao déficit hídrico, uma boa adaptação na região onde será cultivada e qual sua utilização na alimentação, seja humana ou animal. Por ser uma cultura com característica de boa adaptação ás condições edafoclimáticas, o girassol pode ser utilizado em diversos sistemas de produção (AMABILE et. al., 2011).

Em um experimento, Rodrigues et al. (2011) avaliaram o comportamento produtivo de alguns cultivares de girassol, em diferentes ambientes do Nordeste brasileiro, e constataram que houve diferenças significativas para os efeitos de interação cultivar $x$ ambiente, onde, ocorreram mudanças no comportamento das cultivares perante as condições ambientais. Em outro estudo, pesquisadores avaliaram o comportamento de genótipos de girassol, em relação a algumas variáveis como, rendimento de grãos, número de plantas quebradas, entre outras, sob as condições ambientais expressas na safrinha do Cerrado do Distrito Federal, no ano de 2011, e 
concluíram que para as condições da região, o girassol é uma boa alternativa de cultivo para o sistema de produção agrícola (AMABILE et. al., 2011).

Para Faria et. al. (2013) que verificaram o comportamento de genótipos de girassol, no período de safra no ano de 2011, em Mato Grosso, relataram que alguns genótipos do girassol apresentam características favoráveis para cultivo na região.

\section{CULTIVARES}

O girassol vem sendo utilizado em sistemas soja ou soja-milho como alternativa para diversificar a produção. É uma espécie que pode ser cultivada por pequenos, médios e grandes produtores. Pequenas propriedades podem direcionar a produção para a alimentação de aves e/ou humanos. De modo geral, é uma oleaginosa caracterizada por ser muito resistente, seja ao frio, calor ou a seca, o que a torna uma das alternativas de cultivos mais eficazes quando comparadas a outras culturas (LIRA, 2016).

Muitas empresas veem desenvolvendo híbridos de excelente qualidade com potencial para serem cultivadas em algumas regiões, como em Minas Gerais, Mato Grosso do Sul e Paraná. Nesse contexto, recomenda-se a utilização de sementes produzidas por empresas especializadas, uma vez que tais sementes, são produzidas com tratamentos de inseticidas e fungicidas, o que proporciona um melhor desenvolvimento e germinação das plantas. Os gastos de sementes por hectares irá variar correspondente ao tamanho e o peso da semente a ser cultivada, e geralmente, são gastos de aproximadamente 4 a 6 quilos de sementes por hectare (LEITE, et. al., 2005).

\section{CONSÓRCIO}

O consórcio limita o uso de algumas tecnologias, o que resulta em um menor rendimento das culturas consorciadas, porém, para alguns pequenos produtores, pode ser vantajoso, uma vez que se leve em consideração o ganho total por área, e a cultura mais indicada para consórcio com girassol, é o feijão. Para promover maior estabilidade da produção, a difusão da consorciação neste sistema tem como base melhorar a utilização do solo, aumentar a proteção contra a erosão, e promover o favorecimento da ciclagem de nutrientes, que contribuirão na adubação de culturas futuras, no controle de plantas espontâneas além de disponibilizar mais fontes de renda (BRITO, 2016).

No semiárido do nordeste baiano, que tem condições climáticas que condicionam um bom desenvolvimento do girassol, semelhante ao que ocorre com o feijão. No sistema de plantio consorciado com o feijão BRS Requinte foi mais favorável ao cultivo de girassol, no ano agrícola de 2010, constituindo-se em uma excelente alternativa para o cultivo na região do semiárido baiano (CARVALHO, et. al., 2014).

Uma das práticas mais utilizadas, que visam o aumento da sustentabilidade e produtividade, é a utilização de cultivares em consórcios, uma vez que pode possibilitar o crescimento em conjunto de duas ou mais culturas em uma mesma área, de maneira que nutrientes do solo, água e luz, podem ser absorvidos e convertidos em biomassa (NASSAB et. al. 2011).

Em um experimento, Carvalho et. al. (2014) verificaram que o milho consorciado com o girassol, em média produziu cerca de três vezes mais que o girassol solteiro.

Em um experimento, que avaliaram-se a produtividade de alguns cultivares de girassol, quando cultivados em consorcio com mandioca e em monocultivo na região dos Tabuleiros Costeiros do Nordeste, e verificaram uma diferença significativa entre algumas cultivares, com resultados com diferenças genéticas entre elas, em ambos os sistemas de plantio adotados. Os resultados de rendimentos de grãos de girassol, em média, foram de 1.432 quilos por hectare em monocultivo e 1.467 quilos por hectare em consórcio com mandioca, concluindo que, o sistema de 
plantio em consórcio de girassol com mandioca BRS Kiriris foi favorável, tendo resultados maiores e/ou aproximados com os sistemas de monocultivo (MENEZES et. al., 2011).

\section{MANEJO CULTURAL}

As plantas de girassol veem preenchendo muitos de alguns requisitos básicos para sua produção em áreas de agricultura familiar, atuando como uma alternativa para os programas de biodiesel, e com os seus resíduos e coprodutos podendo ser utilizados na alimentação animal, por ter uma característica de boa resistência a seca e a temperaturas baixas, em especial, quando a sua produção tem objetivo ao mercado de óleo e silagem (DOURADO, et. al., 2013).

A planta de girassol está entre as quatro maiores culturas de oleaginosas que produzem óleo vegetal no mundo, por ser extremamente adaptável a variadas condições climáticas, perdendo lugar para as culturas de soja, canola e palma. O rendimento que a cultura do girassol abrange pode ser determinado levando em consideração a produção de grãos, muito embora o grande interesse pela cultura seja o óleo, uma vez que a sua comercialização seja feita com base no peso do grão. Elevadas temperaturas do ar nos períodos de florescimento, enchimento de aquênios e de colheita, proporcionam o sucesso da exploração agrícola (PEREIRA et. al. 2016; DOURADO, et. al., 2013).

A inclusão de agricultores nos programas de Biodiesel é fomentada pelo Selo Combustível Social, porém, existem dificuldades pelas poucas variedades de oleaginosas que possam atender a produção de óleo, que tenham tolerância ao déficit hídrico e que possam fornecer coprodutos e resíduos para serem utilizados na alimentação de animais das propriedades que venham aderir o cultivo dessas plantas. Desse modo, o girassol tem se mostrado uma alternativa para esse tipo de produção, por ter um potencial de atender a essas necessidades, em locais de semiárido, por exemplo, uma vez que seja comum a ocorrência de períodos secos durante as estações chuvosas, os quais, se ocorrerem com bastante intensidade e por um longo tempo, podem provocar dando às culturas de subsistência (SILVEIRA et. al. 2005; SANTANA et. al., 2013).

\section{DEPÓSITO DE SEMENTE}

A qualidade fisiológica das sementes durante o armazenamento é afetada por fatores ambientais, tanto do armazém quanto pela qualidade da própria semente. Caso as condições do armazém não atendam às necessidades de cada tipo de semente, as perdas são efetivas, em consequência das condições de armazenamento (LIRA, 2016).

O cultivo do girassol tem expressão em algumas regiões do país, como a região CentroOeste, sendo que para a garantia de alta produtividade, faz-se necessário o uso de sementes de alta qualidade. Principalmente por conta de características bioquímicas das sementes, pois existe a necessidade de uma armazenagem em condições favoráveis, com isso, é fundamental que seja feita uma boa manutenção da qualidade das mesmas até a semeadura (FERREIRA, 2016; LEITE, et. al., 2005).

\section{ÉPOCA DE SEMEADURA NO BRASIL}

Na cultura do girassol ocorrem algumas interações entre ambiente e genótipo, podendo então ocorrer variação no desempenho de cultivares em função da região e também da época de semeadura (LEITE et al. 2005; SILVA et. al., 2009).

A época de semeadura, é um dos fatores que implicam no cultivo do girassol, entretanto, existem algumas variações significativas que podem ser verificadas na utilização em uma mesma época, variações essas que podem ser ocasionadas por fatores climáticos anuais decorrentes de uma fração irregular de chuvas em algumas regiões, como os conhecidos veranicos. $\mathrm{O}$ girassol, por sua característica de boa adaptação a extensas áreas do território nacional, pode ser cultivado em estações de primavera e verão. (CAMPBELL e ATHAYDE, 2014; LEITE et. al. 2005). 
O cultivo do girassol em épocas fora das preferências indicadas por pesquisas agrícolas realizadas pode implicar diretamente no rendimento de grãos, podendo reduzir a produtividade das plantas dependentes das condições climáticas de épocas marginais, pois é possível a ocorrência de uma menor expressão dos potencias genéticos, aumentando a probabilidade de susceptibilidade de fatores abióticos e bióticos, consequentemente causando perdas significativas na produção (LEITE, et. al., 2005).

Como alternativa ao sistema de produção do Cerrado, o girassol torna-se viável, uma vez que a sua adaptação às condições desse bioma sejam favoráveis. Entretanto, para que se possa alcançar bons resultados, são necessários alguns estudos que tragam informações quanto ao desempenho de genótipos em diversos locais e épocas de plantio, o que possibilita o sucesso nos programas de melhoramento (LIRA, 2016), porém, pesquisas mais aprofundadas devem ser realizadas, para conhecer as necessidades da planta e suas condições ideais, tais como, a escolha da época de semeadura, o melhor arranjo espacial, o genótipo que tem mais chances de adaptação e o uso de algumas substâncias que auxiliam na regulação do crescimento.

\section{PRAGAS}

O girassol é uma oleaginosa bastante suscetível a patógenos e pragas. Os nematoides estão citados como os principais responsáveis pela queda do rendimento dessa cultura em muitos países onde é cultivado. Existem vários patógenos que podem torna-se limitantes à produção. A produção então sofre riscos fitossanitários, como por exemplo a interferência de plantas daninhas e ataque de pragas e doenças. (SILVA, et. al. 2014).

Durante o seu ciclo, o girassol é afetado por diversas pragas, entre elas, a principal é a lagarta preta (Chosyne lacinia saudersii), que provoca uma intensa queda de folhas. Quando a lagarta preta ataca nas fases de florescimento, com aproximadamente 50 a $75 \%$ das flores do capítulo abertas o rendimento de aquênios é muito afetado. (MENDES e ARÉVALO, 2007).

\section{DOENÇAS}

A cultura do girassol tem se expandido muito pelo mundo, porém, pode ser prejudicada por fatores como doenças causadas por vírus, bactérias, fungos e nematoides Alguns pesquisadores relataram que as doenças são as causadoras de aproximadamente $12 \%$ da produção anual de girassol no mundo. As doenças causadas por microrganismos é um fator limitante na maioria das regiões produtoras. Existem relatos de várias doenças que acometem a planta do girassol, como o mosaico, mancha e crestamento bacteriano, podridão da medula das hastes, ferrugem, dentre outras (GULYA et. al., 1997; EMBRAPA, 1983)

Os fungos são considerados maioria, no que diz respeito ao ataque à cultura do girassol, destacando-se o Sclerotium rolfsii Sacc, causador da podridão do colo, que é classificada como uma das principais doenças em praticamente todas as regiões onde o girassol é cultivado. $\mathrm{Na}$ cultura do girassol, quaisquer interferências de fatores abióticos ou bióticos irão refletir na produção final de plantas, bem como ocorre em outras culturas. Dentre os agentes bióticos, se destacam as pragas e doenças, como os fatores que causam redução na produtividade em locais onde o cultivo é tradicional (DA SILVA, et. al. 2014; MOREIRA et. al., 2009).

Uma vez que as doenças são instaladas na lavoura, torna-se difícil o controle das mesmas, ora por falta de produtos que sejam registrados para o cultivo no país, ora pela dinâmica de crescimento das plantas. A resistência genética das plantas é de extrema necessidade, uma vez que possa promover um índice de prevenção a determinadas doenças que possam aparecer na lavoura (LEITE et. al., 2005). 


\section{PREPARO DE ÁREA}

O girassol é conhecido por ser uma cultura rustica e bem adaptável a diversos tipos de solos, porém não deixa de possuir algumas exigências básicas em relação as características do solo que será cultivado e o manejo do mesmo (DE CASTRO et. al. 1996)

Para que a planta consiga expressar seu potencial máximo de cultivo o solo deve atender algumas exigências mínimas em relação as suas características, tais como, áreas planas, solos profundos, estruturados, férteis e bem drenados. Quando atendidas essas exigências o sucesso de cultivo da cultura poderá ser bem maior, pois a planta terá um maior desenvolvimento e maior aproveitamento de sua parte radicular, como consequência gerará maior aproveitamento de nutrientes que lhe são ofertados pelo solo é a tornará mais resistente a ameaças de eventos climáticos (CARAVALHO, et. al. 2015; LEITE et. al. 2005).

O manuseio do solo não irá se diferenciar muito dos outros tipos de culturas. Dependendo do sistema de cultura a área poderá passar por um processo de limpeza se for necessário, caso seja plantio direto essa limpeza será dispensada. Serão realizadas arações profundas de aproximadamente 25 a 30 centímetros e gradeações, sendo que a última gradeação poderá ser feita mais próxima ao período de plantio, para evitar a proliferação de plantas daninhas e deixar a superfície do terreno uniforme (SOARES, et. al. 2016).

É fundamental conhecer os aspectos que estão relacionados à nutrição mineral do girassol, para que com isso, sejam alcançados resultados de sucesso no seu cultivo, aspectos como, a marcha de absorção dos nutrientes, que é essencial para a definição das estratégias de adubação da cultura (NA, 2010).

A aração é um dos pontos mais importantes do preparo do solo para o plantio do girassol, pois a compactação do solo impedirá um bom desenvolvimento da planta, sendo que a mesma necessita de uma profundidade maior para o crescimento de suas raízes. Uma forma de impedir a compactação é alterar os tipos de equipamentos de arações utilizados entre um plantio e outro, como por exemplo, o arado de disco e o de aiveca. Um bom preparo de área, terá bons resultados, como uma germinação rápida, uniforme e com um enraizamento profundo, consequentemente um melhor aproveitamento de água e de nutrientes do solo (LEITE, et. al. 2005).

\section{CORREÇÃO DO SOLO}

O girassol possui um fator que é inibidor do seu desenvolvimento, que é a sua baixa tolerância a solos com pH muito ácido. Para evitar essa toxidez é recomendado que o plantio do girassol seja feito em solos com valores de pH entre 5,2 e 6,4, pois nesses níveis de $\mathrm{pH}$ o alumínio já não trará tantos prejuízos, como por exemplo desencadear uma intoxicação a cultura (PORTO et. al. 2007).

A correção do $\mathrm{pH}$ pode ser feita pelo processo de calagem do solo, a quantidade de calcário que será utilizada deve ser estipulada por meio de análise do solo. A aplicação do calcário pode ser feita de várias formas e em parcelas, respeitando um período mínimo de sessenta dias antes do plantio, o mais comum é parcelar a aplicação do calcário em duas etapas, aplicando a metade do material antes da aração e o restante do calcário depois da aração para haver uma incorporação mais profunda do material, porém, alguns agricultores preferem realizar somente uma aplicação de calcário, a qual é feita logo após a aração (CAMPBELL e ATHAYDE, 2014; LEITE et. al. 2005;)

Uma má correção do solo poderá causar deficiência no sistema radicular da planta, assim delimitando o crescimento e desenvolvimento do mesmo, tornando-a mais vulnerável a pragas e doenças, e delimitando o seu potencial de aproveitamento dos nutrientes presentes no solo (SCAPINELLI et. al. 2016). 


\section{ADUBAÇÃO}

Para que ocorra um desenvolvimento de qualidade a planta vai necessitar de uma boa oferta de nutrientes durante todo o seu período de desenvolvimento até o estabelecimento da cultura. Na adubação se disponibilizará para a planta principalmente os nutrientes como o nitrogênio, fosforo e o potássio (LEITE et. al. 2007).

A quantificação de nutrientes a ser adubada deverá ser adquirida através da análise de solo. Depois de definir a quantidade a ser utilizada na adubação, pode-se então, ser feita a divisão das aplicações, uma vez que a adubação é feita em parcelamentos, normalmente recomenda-se a aplicação de $30 \%$ da adubação durante a semeadura e o restante é plicado em coberturas depois de um intervalo de aproximadamente 30 dias entre as aplicações (CAMPOS et. al. 2015).

Um ponto de grande relevância no cultivo do girassol é a sua sensibilidade a baixos níveis de boro no solo. A falta de boro traz prejuízos como crescimento reduzido da planta, deformação, coloração anormal e a planta se torna muito sensível, ficando facilmente quebradiça. Por tanto, para uma boa elevação do potencial produtivo, é necessário o fornecimento de nutrientes, priorizando quantidades adequadas e qualidade, para que não ocorra a falta ou o excesso de algum determinado elemento (CAPONE et. al. 2016; CASTRO et. al. 2011).

\section{COLHEITA}

A colheita é uma das últimas atividades a serem realizadas no campo, feita após todo o processo de desenvolvimento da planta até o estádio de maturação e produção. A colheita mecanizada de girassol, tanto no Brasil, quanto em países onde a cultura de girassol é tradicional, tem representado desafios por sua característica anatômica da planta e do grão. A colheita é uma prática que sofre a influência de vários fatores, tais como, condições climáticas, teor de água e tipo de colheita (BALLA et. al., 1997; LEITE et. al., 2005; SILVEIRA et. al., 1993).

A época de colheita é determinada de acordo com as condições fisiológicas apresentadas pela planta, ou seja, pelo ponto de maturação da mesma. Sempre que possível, a colheita deve ser realizada quando o teor de umidade dos aquênios, estiver aproximadamente entre 11 a 13\%, levando em consideração algumas condições de desenvolvimento da lavoura, assim, ocorrendo a colheita antecipada ou com atraso, sob teor acima de $16 \%$ de umidade, e abaixo de $9 \%$ de umidade, respectivamente (SILVEIRA et. al., 2005; LEITE et. al., 2005).

\section{CONSIDERAÇÕES FINAIS}

O girassol se destaca como uma cultura importante para o cerrado, pois fornece óleo de alta qualidade e em quantidades bem elevadas, quando comparado a outras culturas oleaginosas. Também apresenta vantagens por sua grande adaptabilidade, podendo ser cultivado em diversos ambientes, o que garante uma produção eficaz e que gera rentabilidade ao produtor que deseja aumentar a sua receita, qualificar a sua área e diversificar a produção. O rendimento pode variar em consequência da escolha do cultivar a ser utilizado, tal como as condições ambientais a que forem submetidas. Com isso, o estudo de genótipos faz-se necessário, uma vez que ainda faltem algumas informações quanto aos tipos de cultura mais adaptadas e quanto a época de semeadura adequada em diversos ambientes.

\section{REFERÊNCIAS}

AMABILE, R. F.; CARVALHO, C. G. P. de; SAYD, R. M.; MONTEIRO, V. A.; RIBEIRO JUNIOR, W. Q. Comportamento de genótipos de girassol em safrinha no cerrado do Distrito Federal em 2011 em ensaio de primeiro ano. Embrapa Cerrados (CPAC) p. 351-353. 2011.

BRIGHENTI, A. M.; CASTRO, C. de 0 girassol como opção em sistemas de integração lavourapecuária. EMBRAPA Gado de Leite, 2013. 
BOYER, J. S. Leaf enlargement and metanolic rates in corn, soybean, and sunflower at various leaf water potencial. Plant Physiology, Bethesda, v.46, 1970.

BALLA, A.; CASTIGLIONI, V.B.R.; CASTRO, C. Colheita do girassol. Londrina: EmbrapaCNPSo, p. 25, 1997.

BRITO, L. F., Plantas de cobertura no sistema de plantio direto orgânico do milho em monocultivo e consorciado com feijão-de-porco (Canavalia ensiformes). 2016.

CAMPOS, V. B.; CHAVES, L. H. G.; GUERRA, H. O. C. Adubação com NPK e irrigação do girassol em Luvissolo: Comportamento vegetativo/NPK fertilization and irrigation of sunflowers in Luvisol: Vegetative behavior. Revista Ambiente \& Água, v. 10, n. 1, p. 221, 2015.

CAPONE, A.; DARIO, A. S.; MENEGON, M. Z.; FIDELIS, R. R.; BARROS, H. B. Respostas de cultivares de girassol a doses crescentes de boro na entressafra do Cerrado Tocantinense. Revista Verde de Agroecologia e Desenvolvimento Sustentável, v. 11, n. 1, p. 43-48, 2016. https://doi.org/10.18378/rvads.v11i1.4004

CARVALHO, L. M. de; CARVALHO, H. W. L. de; OliVEIRA, I. R. de; CARVALHO, C. G. P.; MENEZES, V. M. M.; SANTOS, D. L. dos; MOITINHO, A. C.; MARQUES, M. G.; OLIVEIRA, T. R. A. de; SANTOS, M. L. dos; RODRIGUES, C. S. Comportamento de cultivares de girassol consorciadas com milho na transição Agreste/Sertão. 2014.

CONAB - Companhia Nacional de Abastecimento - Brasília-DF/2016- disponível em:http://www.conab.gov.br/OlalaCMS/uploads/arquivos/16_04_06_17_15_33_girassol_conjunt ura_mensal_-_marco_de_2016.pdf.

CASTRO, C. R.; OlIVEIRA, I. R.; CARVALHO, H. W. L. de; RODRIGUES, C. S.; MENEZES, V. M. M.; CARVALHO, L. M. de; CARVALHO, C. G. P. de; Potencial produtivo do girassol consórciado com feijão no semiárido baiano. Embrapa Soja (CNPSO). 2011.

CASTRO, C. CASTIGLIONI, V. B. R.; BALLA, A.; LEITE, R. M. V. B. C.; KARAM, D.; MELLO, H. C.; GUEDES, L. C. A.; FARIAS, J. R. B. A cultura do girassol. Londrina: EMBRAPA-CNPSO, 1996.

CARVALHO, C. G. P.; OZAWA, E. K. M.; AMABILE, R. F.; GODINHO, V. D. P. C.; GONÇALVES, S. L.; RIBEIRO, J. L.; SEIFERT, A. L. Adaptabilidade e estabilidade de genótipos de girassol resistentes a imidazolinonas em cultivos de segunda safra. Braz J Agric Res, v. 10, p. 1-7, 2015. https://doi.org/10.5039/agraria.v10i1a3804

CAMPBELL, A. T.; ATHAYDE, M. L. Efeito de datas de semeadura no comportamento de dois genótipos de girassol. II. Aspectos nutricionais. Pesquisa Agropecuária Brasileira, v. 23, n. 4, p. 387-396, 2014.

DA SILVA, A. R. A.; BeZERRA, F. M. L.; DE FREITAS, C. A. S.; AMORIM, A. V., DE CARVALHO, L. C. C.; PEREIRA FILHO, J. V., Coeficientes de sensibilidade ao déficit hídrico para a cultura do girassol nas condições do semiárido cearense. Revista Brasileira de Agricultura Irrigada, v. 8, n. 1, p. 38, 2014. https://doi.org/10.7127/rbai.v8n100185 
DA SILVA, F. N. T.; DE LIMA, J. A.; DE OlIVEIRA, E. S. CONTROLE ALTERNATIVO “IN VITRO" DE SCLEROTIUM ROLFSII EM GIRASSOL (HELIANTHUS ANNUUS L.) PELO USO DE EXTRATOS VEGETAIS E TRICHODERMA SPP. Essentia-Revista de Cultura, Ciência e Tecnologia da UVA, v. 15, n. 2, 2014.

DOS SANTOS, C. A. C.; PEIXOTO, C. P.; VIEIRA, E. L.; DA SILVA, M. R.; BULHÕES, I. S.; DOS SANTOS, J. M. D. S.; DE CARVALHO, E. V. Produtividade do girassol sob a ação de bioestimulante vegetal em diferentes condições de semeadura no sistema plantio direto. REVISTA DE CIÊNCIAS AGROAMBIENTAIS, v. 14, n. 2, 2016.

DE CASTRO, C.; CAStigliOnI, V. B. R.; BALLA, A., LEITE, RMVBC, K. D.; MELLO, H. C., GUedeS, L. C. A.; FARIAS, J. R. B. A cultura do girassol. Embrapa-CNPSo, 1996.

DE PAULA JÚNIOR, T. J. 101 culturas: Manual de tecnologias agrícolas. EPAMIG, 2007.

DOURADO, S. B.; SANTANA, P. R. de; SÁ, A. de O.; SILVA, W. P.; SOUSA, S. A.; LEITE, V. M. Correlação de Diâmetro de Capítulo e Produção de Aquênios de Oito Cultivares de Girassol. Embrapa Soja (CNPSO) 2013.

EMBRAPA. Centro Nacional de Pesquisa de Soja. Resultados de pesquisa de girassol - 1993. Londrina: EMBRAPA-CNPSO, 1983.

FARIAS, J. R. B. Déficit hídrico em Culturas. In: Encontro de Plantio Direto no Cerrado, 7, 2005. Tangará da Serra, MT. Proceseedings... Tanguará da Serra Gráfica e Editora Ltda. 2005.

FERREIRA, H. M. F. Comportamento fisiológico e bioquímico de sementes de girassol submetidas ao armazenamento convencional e câmara fria. (2016).

FARIA, D. A. de; FERRARI, M.; PALLAORO, D. S.; RAMOS, J. B.; CARVALHO, C. G. P. de; CAMPOS, D. T. da S.; BORBA FILHO, A. B. Comportamento de genótipos de girassol em Mato Grosso, na safra de 2011. In: REUNIÃO NACIONAL DE PESQUISA DE GIRASSOL, 20.; SIMPÓSIO NACIONAL SOBRE A CULTURA DO GIRASSOL, 8., 2013, Cuiabá. Anais... Brasília, DF: Embrapa, 2013.

GLAS, K. Sunflower: fertilizing for high yield and quality. Worblaufen-Bern: Internacional Potash Institute, 1988.

GAZZOLA, A., Ferreira JÚNIOR, C. T. G., CUNHA, D. A., BORTOLINI, E., PAIAO, G. D., PRIMIANO, I. V., CAMARA, G. "A cultura do girassol." Piracicaba-SP. Junho de (2012).

GULYA, T. J.; RASHID, K. Y.; MASIREVIC, S. M. Sunflower diseases. IN: SCHNEITER, A. A. (Ed.). Soneflower tecnology and production. Madison : American Society of Adronomy, 1997.

KNAPP, F. M., RADONS, S. Z.; ARAUJO, G. M.; MORAES, M. P.; DE OLIVEIRA E. L. B.; PUHL, A. J., RESPOSTAS DO GIRASSOL AO DÉFICIT HÍDRICO EM FUNÇÃO DO TRATAMENTO BIOLÓGICO DAS SEMENTES. Anais da JIC - Jornada de Inciação Científica e Tecnológica, v. 6, n. 1, 2016.

LEITE, RMVB de C.; BRIGHENTI, A. M.; CASTRO, C. de. Girassol no Brasil. Embrapa soja, 2005.

LIRA, E. G. Avaliação de genótipos de girassol em ambientes no Cerrado do Distrito Federal. 2016. 
LOPES, F. B.; SOUZA, F. de; ANDRADE, E. M. de; MEIRELES, A. C. M.; CAITANO, R. F. Determinação do padrão do manejo da irrigação praticada no perímetro irrigado Baixo Acaraú, Ceará, via análise multivariada. Irriga, Botucatu, v. 16, n. 3, p. 301-316, julhosetembro, 2011.

LEITE, R. M. D. C.; CASTRO, C. D.; BRIGHENTI, A. M.; DE OLIVEIRA, F. A.; DE CARVALHO, C. G. P.; DE OLIVEIRA, A. C. B. Indicações para o cultivo de girassol nos Estados do Rio Grande do Sul, Paraná, Mato Grosso do Sul, Mato Grosso, Goiás e Roraima. Embrapa Soja. Comunicado técnico, 2007.

LAURIANE, A. dos A.; DE LIMA, G. S.; CHAVES, L. H.; XAVIER, D. A.; FERNANDES, P. D.; GHEYI, H. R., Fitomassa e produção do girassol cultivado sob diferentes níveis de reposição hídrica e adubação potássica. R. Bras. Eng. Agríc. Ambiental, v. 19, n. 4, p. 336-342, 2015.

MOREIRA, M. A. B.; LIRA, M. A.; ALVES, M. C. S.; TALAMINI, V. Ocorrências de doenças fúngicas na cultura do girassol no Rio Grande do Norte. Comunicado Técnico, ISSN 1678-1937, Aracaju, Dezembro, 2009.

MACCHIA, M.; BENVENUTI, A.; BALDANZI, M. Temperature requeriments during germination in sunflower. In: CONFERENCIA INTERNACIONAL DE GIRASSOL, 11., 1985, Mar del Plata: ASAGIR/ISA, 1985. T. 1, p.93-97.

MENDES, C. D.; ARÉVALO, R. A. CONTROLE ALTERNATIVO DA LAGARTA PRETA (Chosyne lacinia saundersii) DO GIRASSOL. Rev. Bras. Agroecologia, v. 2, n. 1, p. 683, 2007.

MENEZES, V. M. M.; OLIVEIRA, I. R. de; CARVALHO, H. W. L. de; RODRIGUES, C. S.; CARVALHO, L. M. de; CASTRO, C. R.; CARVALHO, C. G. P. Consórcio de girassol com mandioca na ecorregião dos Tabuleiros Costeiros. 2011.

NA, M. D. A. D. M. (2010). CULTURA DO GIRASSOL.

NASSAB, A. D. M.; AMON, T.; KAUL, H. T. Competition and yield in intercrops of maize and sunflower for biogas.Industrial. Crops and Products, v. 34, p. 1203-1211, 2011. https://doi.org/10.1016/j.indcrop.2011.04.015

PORTO, W. S.; CARVALHO, C. G. P.; PINTO, R. J. B. Adaptabilidade e estabilidade como critérios para seleção de genótipos de girassol. Pesquisa Agropecuária Brasileira, Brasília, v. 42, n. 4, p. 491-499, 2007. https://doi.org/10.1590/S0100-204X2007000400006

PEREIRA, D. R., DE GODOY, M. M.; SAMPAIO, C. C.; SILVA, T. V.; FELIX, M. J. D.; OLIVEIRA, R. L. R. de., Uso do girassol (Helianthus annuus) na alimentação animal: aspectos produtivos e nutricionais. Veterinária e Zootecnia, v. 23, n. 2, p. 174-183, 2016.

RODRIGUES, C. S.; CARVALHO, H. W. L. de; OLIVEIRA, I. R. de; CARVALHO, C. G. P. de; FERREIRA, F. M. de B.; TABOSA, J. N.; LIRA, M. A.; CASTRO, C. R.; MENEZES, V. M. M. Comportamento de genótipos de girassol de ensaio final de segundo ano no Nordeste Brasileiro: Safra 2010, Ed. 2011.

SCAPINELLI, A.; DEINA, F. R.; JUNIOR, D. D. V.; VALADÃO, F. C. A.; PEREIRA, L. B. Sistema radicular e componentes produtivos do girassol em solo compactado. Bragantia, v. 75, n. 4, p. 474-486, 2016. 
SOARES, L. E.; NETO, J. V. E.; DA SAILVA, G. G. C.; DE OLIVEIRA, E. M. M.; DA SILVA M. G. B., DOS SANTOS, T. J. A.; DOS SANTOS G. D., CRESCIMENTO E PRODUTIVIDADE DO GIRASSOL SOB DOSES DE NITROGÊNIO E FÓSFORO. Revista Brasileira de Agropecuária Sustentável, v. 6, n. 2, 2016.

SILVA, A. G.; PIRES, R.; MORÃES, E. B.; OLIVEIRA, A. C. B.; CARVALHO, C. G. P.; Desempenho de híbridos de girassol em espaçamentos reduzidos. Semina: Ciências Agrárias, Londrina, v. 30, n. 1, p. 31-38, 2009. https://doi.org/10.5433/1679-0359.2009v30n1p31

SILVA, C.; SILVA, R. A.; VALE, W. G.; MELLO, A. C. T. REAÇÃO DE CULTIVARES DE GIRASSOL (Helianthus annuus L.) A Meloidogyne incognita raça 3 E Meloidogyne javanica-10.14688/19843801/gst. v7n1p7-15. GLOBAL SCIENCE AND TECHNOLOGY, v. 7, n. 1, 2014.

SANTANA, P. R.; SILVA, W. P.; DOURADO, S. B.; SOUZA, S. A.; CRUZ, F. de A.; MENDES, M. F.; LEITE, V. M. - Produção de Grãos e Óleo de Girassol no Semiárido Semeado Fora da Época de Zoneamento Agroclimático. - 2013.

SILVEIRA, J. M.; CASTRO, C.; MESQUITA, C. M.; PORTUGAL, F. A. F. Semeadura e manejo da cultura do girassol. In: LEITE; R. M. V. B. C.; BRIGHENTI, A. M.; CASTRO, C. (Ed.). Girassol no Brasil. Londrina: Embrapa Soja, 2005. p. 375-409.

SILVEIRA, J. M.; BALLA, A.; MESQUITA, C. M. N Adaptação de plataforma de milho para a colheita do girassol. Londrina: EMBRAPA-CNPSO, 1993.

TOMICH, T. R.; RODRIGUES, J. A. S.; GONÇALVES, L. C.; TOMICH, R. G. P.; CARVALHO, A. U. Potencial forrageiro de cultivares de girassol produzidos na safrinha para ensilagem. Arq. bras. med. vet. zootec, v. 55, n. 6, p. 756-762, 2003. https://doi.org/10.1590/S0102-09352003000600013

UNGARO, M.R.G. Girassol (Helianthus annuus L.). In: Boletim Informativo do Instituto Agronômico, Campinas, v.200, n.5, p.112-113, 1990.

VERSLYPE, N. I.; CALDAS, R. M. de S.; JÚNIOR, J. M. C.; ANDRADE, J. S. C. O., Potencial para o cultivo do girassol na Microrregião do Pajeú através do modelo digital do terreno| Potential for sunflower crop in the Microrregião do Pajeú through the digital terrain model. Revista geama, v. 3, n. 1, p. 1-13, 2016. 